It may be of interest to reprint here the following circular which was issued broadcast to bring the aims and intentions of the journal before scientific readers and others :-

The object which it is proposed to attain by this periodical may be broadly stated as follows. It is intended :

First, to place before the general public the grand results of Scientific Work and Scientific Discovery, and to urge the claims of Science to a more general recognition in Education and in Daily Life; and

Secondly, to aid Scientific men themselves, by givin early information of all advances made in any branch of Natural Knowledge throughout the world, and by affording them an opportunity of discussing the various Scientific questions which arise from time to time.

To accomplish this twofold object, the following plan is followed as closely as possible.

Those portions of the paper more especially devoted to the discussion of matters interesting to the public at large contain :

I. Articles written by men eminent in Science on subjects connected with the various points of contact of Natural Knowledge with practical affairs, the public health, and material progress; and on the advancement of Science, and its educational and civilising functions.

II. Full accounts, illustrated when necessary, of Scientific Discoveries of general interest.

III. Records of all efforts made for the encouragement of Natural Knowledge in our Colleges and Schools, and notices of aids to Science-teaching.

IV. Full Reviews of Scientific Works, especially directed to the exact Scientific ground gone over, and the contributions to knowledge, whether in the shape of new facts, maps, illustrations, tables, and the like, which they may contain.

In those portions of Nature more especially interesting to Scientifio men are given :

$V$. Abstracts of important papers communicated to British, American, and Continental Scientific societies and periodicals.

VI. Reports of the meetings of Scientific bodies at home and abroad.

In addition to the above, there are columns devoted to Correspondence.

From the first I was helped by the free kindness of most of the men of science in the country, by their permitting me to appeal to them for assistance and advice, and my election into the Royal Astronomical Society, and afterwards into the Royal Society, in 1869 , brought me into closer correspondence and contact with many of the active workers in scientific fields. I am very grateful for what they did, and for what men of science are still ready to do to ensure that NATURE shall represent scientific claims justly and scientific fact and thought in correct proportion. While this common interest in the journal exists among men of science, not only in the United Kingdom, but also in Europe and America, there will be no falling off from the high standard maintained in its pages from the commencement of its existence.

$$
\text { No. } 26 \text { IO, VOL. IO4] }
$$

\section{PROGRESS AND PROMISE.}

$\mathrm{N}$ the career of a journal, as in the life of a man, stages are met from which it is appropriate to take a glance backward at the road traversed and to contemplate the outlook of the future. Such an epoch has been reached in the history of NATURE, the first number of which was published fifty years ago-on November 4, I869. The circumstances which led to the establishment of this journal are described briefly by Sir Norman Lockyer in the preceding article. Men of science had felt the need for an organ devoted to their interests in common, and several attempts had been made to meet it, but unsuccessfully. It required the rare combination of scientific authority, untiring energy, wise judgment, and business aptitude to construct a platform on which investigators of the many and diverse fields of natural knowledge could put their trust, and from which descriptions of their work would command attention.

How fully these attributes are possessed by the founder of this journal, and how consistently they have been made manifest in its pages, is shown by numerous appreciative messages received from scientific societies and distinguished workers. Thanks to the sound and comprehensive programme laid down by Sir Norman Lockyer at the beginning, and followed ever since, NATURE now occupies a high place in scientific life. It would be disingenuous to pretend that we are not proud of the testimonies which have been sent by many leading representatives of progressive knowledge as to services rendered by the journal in various ways. Among those who have expressed their congratulations upon the attainment of the jubilee are readers who have never missed a number since the first issue, while others of a new generation equally acknowledge the stimulus they derive from a wide view in these days of minute specialisation.

The intellectual background is different now from what it was in 1869 , and the outlook, as well as the conceptions, of science has changed. Specialised work is necessary to acquire new knowledge, but for the great generalisations which provide an impulse to wide inquiry attention must be given to results achieved in the whole sphere of related investigations. It is the particular function of NATURE to present this comprehensive view, and to bring to a focus upon its pages the living picture of scientific advance as a whole, so that workers in separate fields may see the growth of the grand edifice of natural knowledge, and the place their own contributions take in it. 
At one time-as, for example, in the early days of the Royal Society-it was possible for every member of a general scientific society to take an intelligent interest in every paper presented. Since then, however, science has passed from the stage of a simple organism to that of a body made up of parts with highly differentiated functions. Numerous specialised scientific societies have been formed, as may be seen by the list published in this issue of those established since I869, and many periodicals similarly devoted to distinct branches of pure and applied science have come into existence. The common factor is interest in the advancement of knowledge; and a society or a journal concerned with this as a whole can best assist the aim in general by providing the segregated groups of investigators with intelligible accounts of activities in other fields, which may or may not be on the borders of their own.

The remarkable collection of articles published in this issue represents the highest type of contributions of this kind. Each article is by an eminent authority upon the subject with which it deals, and each can be comprehended by everyone who has had a scientific training. It is scarcely too much to say that no such authoritative epitome of fifty years of scientific progress, as viewed by pioneers in particular fields, has ever been brought together in any one periodical. Contributions of such high distinction are rendered possible largely because the writers know that in these pages they are addressing themselves to fellow-workers throughout the world, as well as to other readers having an intelligent interest in the march of scientific knowledge.

Four of the writers-Sir Archibald Geikie, Sir E. Ray Lankester, Prof. Bonney, and Canon Wilson-were contributors to the earliest issues of this journal; and every reader will be grateful for the enlightening descriptions of stepping-stones of scientific progress which we are now privileged to publish. Nature could not have maintained its original standard for so long but for the active support which these and many other leading men of science have been ready to give it since its foundation. This is as true of the new generation as it was when the journal was founded; and the value of the association is most highly appreciated. While NATure is honoured by the active co-operation of the men of genius who are traversing the royal roads of science, its functions will extend, and its influence increase, with the expansion of knowledge. With this assurance, and the encouragement which the past has given, we look with confidence and strength at the prospect of the future.

$$
\text { No. } 26 \text { IO, VOL. I04] }
$$

\section{SCIENTIFIC WORTHIES.}

XLI.-Sir Norman Lockyer, K.C.B., F.R.S. THE simple title Nature, embracing all in a single word, was most appropriately chosen by Sir Norman Lockyer when, exactly fifty years ago, he founded this weekly journal, which is devoted to all the sciences, and has had so successful a career. The first article in the journal reproduced profound aphorisms of Goethe on the intimate relations of man with Nature, of which he is a part. The poet-philosopher set forth in striking language, which was rendered into English by Huxley, the innate feebleness of man before the immutable forces and the great mysteries which everywhere surround him, and at the same time the incessant human desire, never completely satisfied, of comprehending and penetrating them. The contribution is a stimulating preface to a scientific periodical; it well exhibits the high character of the journal at the outset, and the spirit in which it has always been conducted.

Indeed, Nature is, of all scientific journals, the most comprehensive in the world; it includes articles of the highest scientific standard, as well as those of a more popular kind; it has open columns for the discussion of current subjects, and it provides summaries of most of the papers presented to the chief academies and learned societies; it gives the latest events of the scientific world, news about men of science, and accounts of the most recent discoveries in scientific fields. It has rendered inestimable services to the cause of science in general.

Since the first issue the journal has main. tained the form and character which we see to-day. A comparison of a number issued in the year 1869 with one of I9r9 shows the same general arrangement, the same sequence of subject-matter; moreover, the pages and the style of type are nearly identical in appearance. The founder, who in 1869 was only thirty-three years of age, has proved himself a publicist and an organiser of the first rank. During its existence the journal has ably recorded the magnificent discoveries which have distinguished the last fifty years in every branch of science; it has had to deal with subjects beyond one's dreams; and it has been the better able to present them to the public because the founder has himself been one of the foremost builders of this noble edifice.

Sir Norman Lockyer is distinguished not only by his eminent public work, but also as one of the greatest men of science of our time. In the three years which preceded the foundation of this journal he made discoveries relating to the sun which will permanently preserve his memory 